\title{
D. JUAN JOSÉ NAVARRO, MARQUÉS DE LA VICTORIA: ENTRE REFORMISTA Y RESENTIDO
}

\author{
Juan Carlos Maestro Castañeda \\ Universidad de Valladolid
}

Mediante esta breve exposición queremos dar a conocer los puntos principales de la correspondencia privada mantenida durante doce años (1748-1760) ${ }^{1}$ entre D. Juan José Navarro y D. Nicolás de Carvajal y Lancáster, marqués de Sarria $^{2}$, principalmente aquellos que de una forma directa hacen referencia a la política naval española y americana.

Son cartas personales entre dos amigos, lo que las libera del rígido corsé del protocolo y los formalismos ${ }^{3}$, a la vez que nos dan una visión personal del siglo XVIII y de sus principales figuras. Evidencian con claridad la postura de quien las escribe delatando sus fobias y sus filias en un momento crucial para España dinámico y prometedor.

Su literatura cuidada y exquisita está plagada de continuas referencias alegóricas, como corresponde a un hombre con la formación humanística de Navarro, y su estilo, irónico y burlesco en ocasiones, alterna con otras fases de dolor y desencanto.

Como bien se afirma en la nota introductoria, "Para su completa inteligencia es preciso tenerla del sistema político de aquel tiempo y de las personas que influían en él".

Conviene señalar la importancia de estas relaciones, toda vez que la esposa de D. Nicolás de Carvajal, la marquesa de Sarria, mantuvo a partir de 1749, en su casa de la calle del Turco, una tertulia denominada "del buen gusto", donde acudían las personalidades más relevantes de la sociedad dieciochesca madrileña. Allí se daban cita Diego de Torres Villarroel, José de Carvajal (su cuñado y secretario de Estado), Huéscar, Arcos, Medinasidonia, Béjar, Valdeflores, además de un sin fin de literatos y artistas.

1. "Cartas familiares de mano propia del Exmo. Sr. Marqués de la Victoria, Director y Capitán General de la Real Armada, a su amigo el Exmo. Sr. D. Nicolás de Carvajal y Lancáster, Marqués de Sarria, Teniente General de los Reales Ejércitos de SM y Coronel del Regimiento Gs. de Infantería Española, todas bajo nombres supuestos. 1748-1760". Museo Naval (en adelante MN): ms. 2462

2. Fue teniente general de los Reales Ejércitos y participó en las guerras de Italia así como en la invasión de Portugal.

3. En esta relación epistolar, Navarro utiliza el seudónimo de "Moscón", y a Carvajal le atribuye el de "Palanco". 
El "buen gusto", era el clasicismo impulsado por los jóvenes pensionados por la Academia que regresaban a Madrid deslumbrados por las novedades de artistas parisinos, romanos y napolitanos.

Un contemporáneo manifestaba su asombro al ver la rica colección de pinturas y esculturas que la marquesa atesoraba en su casa, aunque lo que verdaderamente le fascinó fue la biblioteca, "la cual contaba con todas las obras poéticas de los españoles. . ."

A esta nómina de ilustres personalidades debemos unir la de Cadalso, quien también mantuvo una frecuente relación epistolar con el marqués de la Victoria.

\section{Rasgos biográficos de D. juan José Navarro}

No es nuestro objetivo realizar una minuciosa biografía sobre el autor de la correspondencia analizada ${ }^{5}$, pero sí nos parece de obligado cumplimiento entresacar los hitos y hechos más relevantes y significativos de ella.

Este excepcional marino nació en Messina el 30 de noviembre de 1687. A los ocho años ingresó en el Tercio del Mar de Nápoles y participó en las guerras del Milanesado, en la expedición de socorro a Orán (junto a su padre y su hermano), en las conquistas de Alicante y Valencia, así como en la sublevación catalana.

En 1717 ingresa en la Armada pasando a formar parte del profesorado de la Compañía de Guardiamarinas, e interviniendo con ella en la conquista de Cerdeña; al mando de los navíos San Fernando y Castilla tomó parte activa en la expedición contra Orán. Al iniciarse la guerra de la Oreja de Jenkins (1739) se le encargó el mando de la escuadra de Cádiz, la más importante.

Quizá su gesta más conocida sea el enfrentamiento con el almirante inglés Thomas Mathews en cabo Sicié (20 de febrero de 1744), rompiendo el cerco a que se veían sometidas las naves francesas y españolas en Tolón, y en la que la participación de la escuadra de Mr. La Bruyeres de Court en apoyo de la nuestra, quedó en entredicho. Tras la batalla, donde resultó herido D. Juan José Navarro, se le ascendió a teniente general (con el aplauso de todos) y se le dio el título de marqués de la Victoria (hecho no tan aplaudido) ${ }^{6}$.

4. GOMEZ URDAÑEZ, José Luis: Fernando VI, Ed: Arlanza, Madrid, 2001, p. 256 y ss

5.- FERNANDEZ DE NAVARRETE, M.: Biblioteca marítima española, T.II, p. 275 VARGAS PONCE, J. de: Varones ilustres de la Marina española, Madrid, 1808 OYARZABAL I. de: El Capitán General de la Armada D. Juan José Navarro, marqués de la Victoria, Madrid, 1968

6. FERNANDEZ DURO, Cesáreo: La Armada española desde la unión de los reinos de Castilla y León, Madrid, 1895-1903, T.VI, p.304 
En 1750 fue nombrado capitán general de los departamentos de Cádiz y Cartagena y director general de la Armada. Con motivo del acceso al trono de Carlos III comandó la escuadra que trajo al nuevo monarca desde Nápoles a bordo del Fénix. El rey, en agradecimiento, le ascendió a capitán general.

Aparte de los hechos notables de armas expresados y de su magisterio en la escuela de guardiamarinas, sobresalió como científico, inventor, dibujante y constructor naval ${ }^{7}$. Realizó estudios de matemáticas, filosofía y humanidades; redactó un código de señales para gobernar el movimiento de las escuadras y un diccionario sobre arquitectura naval. En 1740 su contribución a la ciencia náutica se vio recompensada con el ingreso en la Real Academia Española ${ }^{8}$. Falleció en la isla de León el 5 de febrero de 1772.

\section{El 'destierro' de la corte. La oposición a Ensenada}

La correspondencia entre ambos personajes se inicia ${ }^{9}$ en 1748 , año de la Paz de Aquisgrán y de la promulgación de las Ordenanzas de Marina por D. Joaquín de Aguirre.

Hemos de considerar unánime la opinión de que el estado de la Marina española a finales del siglo XVII era, como poco, lamentable, a lo que se vino a sumar el desastre ocurrido en Vigo en 1702, reduciendo aún más el escaso número de efectivos disponibles. A todo ello vino a poner remedio el nombramiento de Patiño como intendente general de Marina, y con posterioridad los de Campillo y, sobre todo, Ensenada ${ }^{10}$ en el ministerio. En Aquisgrán España conseguía la tan anhelada paz, de la que pensaba sacar tan buen provecho, sobre todo ahora que se había apartado del poder a la intrigante Farnesio y sus "afligidos" ${ }^{11}$. Hacía solo dos años que había fallecido Felipe $\mathrm{V}$ y ascendido al trono su hijo, Fernando VI, en quien tantas esperanzas se tenían puestas, aunque pronto sus primeros"vapores" alertaron sobre la quimera de una euforia excesiva.

Desde su atalaya gaditana, D. Juan José Navarro no ve su destino como un premio o el resultado de sus méritos, sino que anhela estar en

7. MN: mss 889, doc. 1, 1755

8. GONZALEZ-ALLER, José Ignacio: XIV Jornadas de Historia Marítima. D. Juan José Navarro, Marqués de la Victoria en la España de su tiempo, Instituto de Historia y Cultura Naval, № 28, Madrid, 1996, p.3

9. Por el contexto hemos de entender que la relación entre ambos venía de antiguo y que con certeza continuó en lo sucesivo.

10. La publicación más reciente sobre Ensenada se debe a José Luis Gómez Urdáñez: El proyecto reformista de Ensenada, Milenio, Lérida, 1996. Se trata de una obra excepcional en cuanto puesta al día de la cuestión y sistematización de los diversos enfoques de la obra del ministro.

11. Así se conocía a los partidarios de Isabel de Farnesio que se ubicaron en el palacio del duque de Osuna, en la plazuela de los Afligidos. 
la corte de la que se ve desplazado y donde todo se hace y se desha$\mathrm{ce}^{12}$.

"Ten resignación sin flaqueza, asta que el restante del mundo mejore, porque a la España está negado esse consuelo, y sería formar la torre de Babel unir y reglar la desorden de todo su Gobierno, para hazerla Mausoleo de Bondad. Siempre ha de haver insectos en los más hermosos campos; tachas en la leche y moscas en la miel, y pues hubo asta en los Angeles tantos que se bolbieron Demonios; si Dios no los echa en los Infiernos, los que obran como tales, todo lo han de ensuziar como arpías, todo lo han de rapiñar como gavilanes, y todo lo han de tragar como buytres. Yo pájaro metido en esta jaula si los amos no me dieran de comer, muriera mártir del desseo ${ }^{\prime 13}$

El motivo de tanta queja no era otro que D. Cenón de Somodevilla. Victoria pasaba por ser un empedernido carvajalista y no disimulaba sus críticas y puyas más aceradas hacia el marqués, haciendo alusión a su baja extracción social y a su falta de formación, a la vez que eximía de culpa al rey.

"Yo quedo satisfecho de la honra que me hace tu Eximo. Socio de tenerme en su memoria, más aprecio este favor que todos los Inciensos"

"Toda la pesadumbre que tengo es ver a tu digníssimo Hermano y a ti desazonado, en ver la enlazada cadena que está formando sin poder deshazer (de absoluto) sus hierros"

"Pero es el destino de estos Reynos, que solamente los estuerzos naden y floten; que solamente brillen los cuernos de la luna... que los disparates se celebren como prodigios de la mayor Inteligencia"

“¿Pero cómo es posible que produzca un idiotismo destellos de la sabiduría?z Nunca de rabo de Puerco buen virote. Y assí, amigo, Doctor mío,Paciencia, y a esperar que Dios baraje los naypes. El guardar y conservar su Ropa es la Gala del Prudente nadador. Hágalo assí tu venerado socio, que al fin a cada Puerco le ha de llegar su San Martín. Tu que estás en la fuente ves manar los disparates y las injusticias, nosotros lejos de ellas vemos correr los torrentes, lo quales conocemos no son producidos de la fuente. . ."

". . . mayores adulterioss e hacen en los Ministerios, donde lo que engendran o sale en su nombre o havría de declarar su Padre. . porque árbol que se crió sin cultura ni estudio es impossible que no salga irregular, defectuoso y cargado de amargas frutas" ${ }^{14}$

Mal objetivo escogió Navarro en su propio ministro para verter su encono, toda vez que Ensenada estaba enterado de todo ${ }^{15}$, merced a que se había

12. La corte era centro de atracción y el lugar idóneo para solicitar y conseguir favores y cargos. Hasta tal punto era así, que son numerosas las órdenes expedidas por el ministerio de Marina ordenando a determinados individuos que se restituyan a sus servicios amenazándolos con diversas penas, toda vez que han hecho caso omiso a los sucesivos requerimientos de que la abandonen.

13. Correspondencia del año 1748

14. 23 de julio de 1749

15. "Metido estoy entre Caribes, con más espías que un Navío que entra por passos estrechos. Confieso estoy acoquinado y zurrado de miedo, metido en presa como tafetán de aguas, y que echo un fantasmón de nombre otros dirigen allí lo que aquí se debe hazer. Quién hubiera creydo que porque te escrivía me fue dicho que el no ser atendido nazía de esta correspondencia"

"yo no quito Rey ni pongo Rey, pero a ti y a tu venerado compañero venero y amo porque tengo obligación de haz. Como no ignoras que no he dejado de morder el sistema de estos tiempos sospeché, o que alguna de las cartas que te he escrito hubiesse caydo en sus manos o que alguno por congratularse con el Poderoso hubiera ponderado mis libertades". 
rodeado de una sólida clientela ${ }^{16}$ a la que Huéscar denominaba "la farándula de don Cenón", y era un hombre pragmático, curtido en la guerra, poco dado a filosofías y maestro de la doble intención. ¿Cómo iba a permitir en estas circunstancias albergar en la propia corte a un enemigo enconado?. Aunque, como se colige de la correspondencia, la pasión de Victoria era más fruto de la vinculación familiar que del convencimiento en la práctica política que preconizaba D. José de Carvajal.

En estos momentos tanto él como Ensenada ensayan con éxito el nuevo sistema de "paz activa". Ambos persiguen objetivos idénticos, pero por distintos caminos. La historiografía tradicional ha estereotipado la fracofilia del primero y la anglofilia del segundo. Es necesario mesurar ese maniqueísmo, pues no es legítima esta contraposición, ya que ni el uno ni el otro traspasaron los límites razonables ni llegaron al enfrentamiento. Sólo al final, cuando el ministro de Estado se dio cuenta que su fórmula se iba al garete, lo achacó a las maniobras de Ensenada ( sus picardigüelas) y fue muy crítico con él. En su sistema de paz cada uno de ellos mira hacia el aliado que le puede resultar más eficaz, sobre todo para la defensa y explotación del reino indiano. A Ensenada le parece que la única forma de mantener a raya a Inglaterra es un contar con la alianza francesa; desconfía totalmente de Inglaterra y sabe que tarde o temprano llegará la confrontación, por lo que aspira a una preparación militar para que la balanza se incline hacia España tanto si había paz como si había guerra. Sobre todo si había guerra, haciendo de la Marina su principal instrumento. El ministro de Estado (seguidor de Saint Pierre), desea un equilibrio astuto (símil de la lancilla de la balanza), con la diplomacia por arma y apoyándose en el humanismo cristiano, idea que a Ensenada le resultaba una quimera. Los dos están convencidos de la imperiosa necesidad de la paz, y en el momento presente, de la neutralidad como su medio.

Los años 1746-47 fueron de relumbre para Carvajal, que veía su estrella brillar en lo más alto. A partir de ese momento, la acción soterrada de Ensenada comenzaría a dar sus frutos, poniendo en práctica, entre otras medidas, las levas contra los vagos ${ }^{17}$, de las que ya había tenido conocimiento se llevaban a cabo en Francia, aplicando también aquí el practicismo dieciochesco: "siempre habría pobres, dijo Cristo, pero que fueran útiles, dicen ahora los ilustrados" ${ }^{\prime 18}$. Tomó nota de las disposiciones adoptadas por Portugal para la expulsión de los gitanos, autorizando en 1746 a matarlos si se hallaban fuera de su lugar de avecindamiento, y sobre los que llegó a

16. En la actualidad, bajo la dirección de José Luis Gómez Urdáñez, se realizan en la Universidad de la Rioja una serie de tesis doctorales sobre las "echuras"de Ensenada y su red clientelar.

17. PEREZ ESTEVEZ, Rosa María: El problema de los vagos en la España del siglo XVIII, Confederación Española de Cajas de Ahorros, Madrid, 1976

18. GOMEZ URDAÑEZ, José Luis: El proyecto político. . . , p. 121 
concebir auténticos planes de "extinción" ${ }^{19}$, medida de la que también se hacía eco Navarro:

"metido en este Destierro de Gitanos y miserable Pays todo el tiempo se me va por las bardas del corral en pensar, qué descomunal estrella domina nuestra miserable situación. Preguntándome cada instante, si ha resucitado Nerón, si se ha levantado otra persecución nueba contra el Catholicismo, o si todos los Diablos del Infierno tienen el poder de bolvernos locos, fátuos y pacientes asta que todos quedemos sodomizados de las caprichosas ideas del mandón. ¿No hay por hay confesores, no hay sermonistas que atajen (siquiera por compasión) el torbellino de tanto desorden? Dime (por quien eres) de quien es el bello pensamiento de prender los Gitanos sin antes haver pensado dónde ponerlos y destinarles oficio. ¿Hay texto en el evangelio que permita dar muerte civil a una Generación (bien es verdad conocida por buena) sin que la sindéresis de Próximos le (- - -) escrúpulo de aniquilarlos?. Es bueno que el Rey que forma tropas destruye méritos de los que se han sacrificado por la Corona y mantiene el importe de más de 40.000 hombres de armas por mantener un pueblo que pudiera darle utilidad si divididos en ciudades grandes y puestos en arrabales (como judíos encerrados) se capitassen, permitiéndoles sus oficios, pero no el que de noche se hallasen en la ciudad, ni fuera de ella (con penas de muerte). Se mata de hambre a infinidad de oficiales beneméritos estropeados, y se ganan a millaradas los pesos duros en mantener toda una Gitanería que para que se destruyan es menester que pasen 60 ó 70 años".

Pero las discrepancias también se extendían al ámbito profesional, criticando con acidez el destino de oficiales para puestos que él considera inmerecidos, y debidos al exclusivo mérito de su amistad con Ensenada, así como las retribuciones que por ellos perciben:

"Un regalo te hiziera si me enseñaras el secreto (que sí se podrá saber) por dónde o por qual vereda se encuentra la fortuna de los Pizarros y Arriagas. Al uno, dándole a manos llenas los 50 mil pesos para su viage con sueldo mayor de lo que tienen los Virreyes, y a éste dándole dos mil doblones de gratis et amore por los gastos echos en el Mediterráneo y los por hazer en Indias. Y otros, cornudos que se han gastado asta la rayz de sus astas, no pueden alcanzar ni aún la memoria agradecida de que por el lustre del Rey y de la nación se han esforzado a ser Generosos. ;Dar dos mil doblones a uno que no ha gastado ni aún las palabras con que conversar con sus oficiales!. Lo harán Gefe de Escuadra, y así la Marina estará compuesta de Oficiales Generales, unos viejos, y entre ellos yo que desnudo como un nadador nada tengo y nada tendré, y los demás, unos ciegos, pero linzes para regalar, otros cojos y otros sordos, pero por esto más atendidos por ser dignos de la atención y amistad que los tienen por esclavos suyos y de todos sus prosélitos ${ }^{\prime 20}$.

"Aquí tenemos Gefes, Intendentes, Capitanes de Navío, Comissarios Ordenadores, Oficiales de Pluma, Capitanes de fragata y no imbidiamos al Campo de Ocaña, donde dizen lo mandará el Capitán General de los Capitanes Generales.!Viva España y viva su buen Gobierno; que ha venido y vuelto el tiempo de Adam ${ }^{21}$, donde se casaban hermanos y hermanas, y ahora sucede lo mismo, se hermanan plumas y plomos ${ }^{12^{2}}$.

19. Idem, p. 215

20. 1 de octubre de 1749.- Evidentemente se refiere a la campaña de corso que en ese momento realizaba Arriaga en el Mediterráneo con los navíos América y Constante, apoyado por los jabeques de D. Antonio Barceló. Vid. MAESTRO CASTAÑEDA, Juan Carlos: "Orígenes y formación marinera de un gran hombre de estado: Julián de Arriaga (1700-1749)", en Euskal Herría y el Nuevo Mundo. La contribución de los vascos a la formación de las Américas, Vitoria, 1996, pp. 285-291

21. Adán era otro de los sobrenombres por los que se conocía a Ensenada; Adán al revés es "Nada". El mismo ministro bromeaba con su nombre diciendo que él era "en sí nada". Otros motes fueron Tinto, Clarete, Garnacha. . . , que hacían referencia a su origen riojano.

22. 14 de diciembre de 1751 
Las críticas al gobierno son continuas, sobre todo porque es consciente que la hora de Carvajal ha pasado y que los resortes de la nación están en otras manos, como diría el P. Isla, en el "Secretario de todo". Ya lo único que pide es que Carvajal no le olvide "Toda mi esperanza (si no muero del traspasso de los viejos) despues de Dios está en tu uterino compañero, que confío no me dejará morir con una familia llena de vanos honores, y sin tener con qué dejarles un pedazo de pan ${ }^{\prime{ }^{23}}$ Para estos males sólo encuentra un remedio, paciencia y a esperar tiempos mejores.

"Vala Dios, y que bien andan las bragas del Gobierno y qual andan los corazones de todos, murmurando más que un río despeñado y maldiziendo como condenados el tiempo, y a quien lleva las riendas, porque el Ginete es una estatua.

Denos Dios salud, adorado Palanco mío. Con ella veremos en qué paran las cosas. A tu adorado socio, mil cosas. Más sentimiento tengo de los disgustos que tendrá viendo cómo va todo sin poderlo remediar ${ }^{24}$

En su ansia de relanzar la Marina, Ensenada había pergeñado un plan meticuloso, merced al cual, y al buen hacer de Jorge Juan, se pudo traer a constructores navales ingleses para instaurar aquí el método de aquel país, que pasaba por ser el más adelantado del momento. No se escamotearon medios ni dinero en el empeño que culminó con la llegada de Ricardo Root, a quien se consideraba el mejor, a Ferrol, Mateo Mullan (Cádiz) y Edward Bryant (Cartagena) a los astilleros españoles, inagurando la llamada época de "construcción inglesa" ${ }^{25}$

El marqués de la Victoria, hombre perspicaz donde los haya, no se deja llevar por la propaganda ensenadista de euforia desmedida, y con tino puntualizaba:

"La construcción Inglesa es menester experimentarla por hazer juicio formal de ella. Los Navíos asta ahora construidos son mediocremente buenos pero cada uno cuesta un ojo de la cara.. Las fragatas, pocas han salido como se deseavan, y assí unas son mediocres y otras no (. . .) buenas. Se vuelve a repetir que el tiempo manifestará lo que serán unos y otras. Si tienen algún defecto, los que los montan lo callan porque ninguno quiere poner el cascabel al gato, y primero se volverán Turcos que decir mal de ellos. Lo que antes París y francia era lo más excelente, ahora Londres e Inglaterra es lo más superior".

\section{El bailío crucífero. historia de un desencuentro}

El 8 de abril de 1754 muere repentinamente Carvajal, y las esperanzas de Navarro se truncan de raíz. Pero apenas unos meses más tarde, en julio de ese mismo año, la diosa fortuna quiere que se desate la gran tormenta que dará con

23. 15 de noviembre de 1751

24. 1 de octubre de 1749

25. MERINO NAVARRO, Jose P.: La Armada española en el siglo XVIII, Fundación Universitaria Española, Madrid, 1981, pp. 49-51 
Ensenada en su destierro granadino ${ }^{26}$, con el especial deleite de ser su amigo del alma, D. Nicolás Carvajal, el encargado de prenderle.

"que serenada por ti la tempestad del Gobierno passado, libre del Dispotismo Nerónico, en que todos padecían Martirio, gozas del descanso, donde sentado en la poltronería te ríes de los Doctores, te ensucias de las cosas del Mundo, y aún de mi amistad". ${ }^{27}$

Este último acontecimiento debió renovar la ilusión de D. Juan José, que no ve claro cómo Ilegarán a entenderse los cuatro Secretarios (Wall en Estado, Eslava en Guerra, Valparaíso en Hacienda y Arriaga en Marina e Indias)

"ríete de lo que passa y ves por que quanta más vida, tendremos tantas más extravagancias veremos. En verdad que yo también doy de quando en quando meadas a la pared y discurro como viejo malicioso, y digo en mí, ;Válgame Dios, toda mi vida he oydo dezir que mal se sentavan dos tafanarios en un asiento, cómo oy día se sentarán quatro!. Precisamente havrá divissión de lenguas, uno pedirá tropas, otro navíos, otro Mosca para espías y el que tiene la llave del arca del Pan, siempre encogido de hombros, responderá: amigos, no hay carne ni tozino para esta olla.Y assí no hay que extrañar que todo será proyectos (. . . ) dos de nieve, donde el Despacho irá con paso de plomo para no acabar de romper el tejado de vidrio sobre el que antes les abrillantava el Gobierno passado"

Parece que pensara en unificar todos los asuntos de gobierno en una sola mano, evidentemente en las de Carvajal: "iOh, Dios, si no hubiera fallecido tu incomparable hermano, en qué buenas manos hubiera caydo la Monarchía".

La enemistad con Arriaga comenzó desde muy pronto. Ya hemos visto sus pocas simpatías con motivo de la campaña de éste en el Mediterráneo, y que probablemente no aumentarían al saber su nombramiento como jefe de escuadra en Venezuela ${ }^{28}$. Ciertamente su trato, por lógica más intenso, no debió mejorar con posterioridad cuando fue designado intendente de Cádiz. Ahora con él en el ministerio los problemas se multiplican. Navarro le envía un memorial en el que expone sus méritos para la concesión de la capitanía general de la Armada, poniendo en duda de que Arriaga lo eleve al rey

"Adopto tu prudente consejo en animar ( si no lo hace essa Sierra Nevada de Ministro), en dar mi memorial. . . . Te confieso que havía tomado todos los medios más proporcionados por si la inacción o lentitud de la Zona fría del (ministro) lo dejase para otra ocasión $n^{\prime 29}$

Pero el ministro, al que ya le constaban las críticas de su director general, de modos suaves y conocedor de que sus informes tenían gran influencia en el rey ${ }^{30}$ aprovechó el envite para con un nuevo nombramiento no darle nada. En la correspondencia con su amigo Carvajal, Navarro truena con el enfado que le produce la tomadura de pelo y se manifiesta con tanta virulencia, que por su interés reproducimos:

26. El "En-sí-nada" acababa en la "Gran-nada"

27. 2 de octubre de 1754

28. 2 de octubre de 1754

29. 1 de diciembre de 1756

30. RODRIGUEZ CASADO, Vicente: La política y los políticos en el reinado de Carlos III, Rialp, Madrid, 1962, pp. 88-89 
"tengo aviso que me han echo Governador General de la Armada, y voy a preguntarte qué espezie de animal es el tal empleo. Lo hay en nuestra Marina y me he quitado la vista buscando asta en el Diccionario de Moreri, y el latino de Nebrija a qué corresponde en tierra este retumbante nombre de Governador y lleve el Diablo (al que ha llevado) si he podido encontrar su Definición. En mi sentir el Governador, el Director, el Comandante General y el Comandante en Gefe de la Marina son sinónimos, que quiere dezir uno que manda sobre lguales e inferiores, pero todos tres son una misma cosa, como llamar tafanario, trasero, nalgatorio, posaderas y reble, que todos significan culo. Pedí al Rey por mano de nuestro carambano de Ministro ser Capitán General, no Governador. Dizen que el Rey con agrado me lo conzedió (tal vez no sabiendo los empleos que tiene el Cuerpo de Marina) pero el Sr Baylío devió por su escrúpulo de conciencia hallar por más retumbante nombre el de Governador que el de Capitán General. Por fin toda la Gracia que me han echo es que los Guardia me toquen la marcha (que es el mismo honor que me hazen en los Navíos y Arsenales). Y cátame aquí echo un Governador de Marina . Excusada era esta gracia pues lo mesmo tenía antes y a mi me dan dos bledos que me toquen la marcha o la llamada en las Plazas y Puestos, o que me toquen las chirimias. Te asuguro Palanco mío que me he quedado elado y lloro mi mala fortuna de que despues de tantos travajos, servicios, heridas y méritos me dan (lo que me devían dar luego que me hizieron Director) y me conzedieron el sueldo de Capitán General. Te suplico amado Palanco mío que publiques que no me han dado nada más que lo que ya tenía. Y toda la Paparucha es que en las Plazas me toquen la marcha. Te asseguro que estoy amohinado y aun quasi corrido, pues todos dizen lo mesmo.

Repara pues, si he tenido desconfianza en el Baylío, y si es justa; a él como le han dado los Grados sin desembaynar la espada le pareze en otros mucho, y a él que tiene poco ${ }^{\prime 31}$.

" ya te escribí, Palanco mío, la resulta de mi memorial, en que pedía Zevollas y me dieron Puerros. Si es el amo que lo ha echo, chitón y paciencia y barajar. Allá van leyes donde quieren Reyes. Pero si fue echura del artificioso Ministro con hazerle creer al Rey que sea lo mesmo Goverandor que Capitán General, no puedo tragar el maldito anzuelo","32.

La situación se va haciendo cada vez más tensa, y con ocasión de la solicitud de la llave de gentilhombre de cámara y la revisión de unas pensiones para sus hijas, Victoria se da cuenta de la sequedad de Julián de Arriaga en sus respuestas, lo que no le frena en sus críticas

"y que nos ha caydo la suerte de tener un Ministro Santo, pero que lo es para sí, y para los otros ni carne ni pescado. ."

"Con esta experiencia y con el conocimiento que tengo de su natural, de sus recónditos Políticos ofrecimientos estoy en la desconfianza de que no haga nada por mi. Encogido de Genio, no se atreve a nada, iuste vel iniuste Se halla exaltado y se le da un comino que otro, aunque lo merezca, lo esté. Está puesto de la mano de Dios donde está y (aunque) no hay que echarle en la cara el por dónde ha subido al escalón donde se halla".

"Toda esta relación que te hago va a concluyr diziendo que si da mi Memorial al Rey, no tienes tu de cansarte en darlo, pero si acaso su cortedad o Política de no pedir por nadie le enfría la Gana, entonzes me tomaré la libertad (si tu me lo apruebas) de imbiarte el igual Memorial y copia de las cartas escritas, a fin de que por tu mano sepa el Rey el que le passé otro igual por la dirección de la mano por la qual devía $i^{\prime \prime^{33}}$.

31. 8 de diciembre de 1756

32. 22 de diciembre de 1756

33. 7 de marzo de 1757 
En 1757 la cuerda se ha tensado tanto que Navarro comunica a su amigo que está dispuesto a no proponer candidatos para los ascensos regulares

"A mi situación, si el crucífero Baylío no me manda por orden del Rey a que haga propuestas de Oficiales, no tengo la libertad de proponerlos, aunque sus méritos saquen un alma del purgatorio y sean sus procederes dignos de una tiara". ${ }^{34}$

Está casi desesperado y agobiado económicamente, por lo que no escapa a su crítica ni la misma institución eclesiástica, a quien hace responsable de tanto doblez utilizando para ello el manto de la religión

"El insomnio de nuestra Monarchía . La avaricia de no dar nada, haze que la justicia, el mérito y la buena fe anden vagando en los Payses extranjeros, porque aquí el solo nombre va a peligro de quedar estrangolado. Cubre todos estos principios la capa de la Religión, no hay ningún Español que no tenga a Christo y a María en la Boca, pero todos se inclinan a que el Christo sea de oro y la María de Plata. El hurto passa por perche del ofizio; el chupar la sangre de los pobres, por augmento de la hazienda Real; todo es Mezquindad para otros, pero para sí, son pocos los tesoros de Midas y las riquezas de Credo, y se les da dos cominos que todo el mundo diga que tiene las orejas de asno. Ande pues la rueda como quisieren y viva nuestro catolicismo, que con oir Missa y rezar el Rosario, aunque sea el mayor adúltero y más ladrón que Caco, como tenga Pesetas que dar o cosa que lo valga, todos entrarán por las puertas de la Gloria mundana y celeste, porque por todas Puertas entran las llaves o Ganzúas de oro.

Mordaz me he buelto, pero no tanto que no pudiera decir cosas millones de vezes mayores. Las verdades amargan, y con el Rey y la Inquisición, chitón, y con el que gobierna la carreta, que se apropia la muleta, porque en siendo de otro Dueño, le da sueño".

\section{Una esperanza baldía: Carlos III, el nuevo rey}

La precaria salud de Fernando VI que ya había dado sobrados motivos de preocupación, se precipita con el fallecimiento de su esposa, Dña. Bárbara de Braganza, y recluido en el castillo de Villaviciosa de Odón, deja paralizada toda la maquinaria estatal esperando una recuperación o el trágico final. Es lo que se ha dado en Ilamar por la historiografía "el año sin rey" (1759) ${ }^{36}$. Navarro transmite esta misma preocupación a su amigo Nicolás, y prevé que con la falta de Fernando y la llegada del nuevo monarca entraremos en una guerra para la que no estamos preparados.

"Te considero angustiado con lo que passa sobre la salud de nuestro amo. Todos lo estamos, porque con su falta, toda la neutralidad se la llevó Barzoque, y prresto entraremos con los demás en contradanza. Nunca me ha parecido bien la flojera de nuestros Secretarios haviendo dejado a que passen los días sin pensar en la tropa, tren de Artillería. El Exército sin armas, la Tropa llena de Vagavundos y facinosos, y un espantajo de Navíos sin Oficiales suficientes para siquiera la mitad de ellos. No Señor la economía ha sido el Tropezón donde ha dado de hocicos el Gobierno. Veremos (si tenemos Guerra) cómo sacaremos el culo de las ortigas. El caso es que ni

34. 19 de septiembre de 1757

35. Idem

36. Sobre el proceso de la enfermedad de Fernando VI y la correspondencia entre Wall, Tanucci y Carlos III, véase AGS: Secretaría de Marina, leg. 609 
en tierra ni en Mar hay muchos Gefes de quien echar mano. La de Dios sea que nos guye, porque la vida de un hombre es corta para remendar tánto roto y tánto desbarro en todo género de classes $^{\prime \prime}{ }^{37}$

"El Santo Dios va a pretando la clavija, de modo que estamos con Rey y sin Rey, y con esto, todas las Ruedas del Reloj del Gobierno van a la Diabla ${ }^{\prime 1^{38}}$

A la preocupación por la salud del rey le sucede la del futuro inmediato. Si éste fallece, como era probable, ¿a quién le corresponde sino él acudir en su traslado desde Nápoles?. Sabe que es una oportunidad de oro que no puede desaprovechar para obtener el favor regio desde el primer día y las inevitables bondades económicas que de la generosidad real habrían de desprenderse. Pero, como siempre, emerge la figura de Arriaga. Navarro le insinúa esta posibilidad, pero la sequedad del ministro le descompone, e intuye que será una negativa, dándole esa gracia a D. Andrés Reggio. Recurre a su amigo para que le haga llegar un memorial a la reina viuda en este sentido

"Aquí te incluyo esse memorial lacónico y breve, por si Barzoque que ha puesto una renziIla oculta con el frayle y entre mi Paciencia. Temo no me haga la zancadilla de dividir los Navíos en escuadras, para juntarlas y luego dar el mando al Teniente General más antigua. Este bendito frayle ha estudiado en el Gimnasio del Padre Gargajo, y en el areópago de su Religión, donde los puntos de su decálogo consisten en buenas palabras y ninguna buena obra no sea ventajosa para sí o para su utilidad.

Nulla fides, in jorobatis.

Nulla véritas, in zambis.

Nulla bonitas, in vizquis.

Si Melitanus bonus est, Inter. Mirácula scribe". ${ }^{39}$

Por fin un día escribe a Carvajal exultante; va a Nápoles a por el nuevo rey:

"Dios Poderoso, tus buenos oficios y mi ventura, me han sacado del Limbo donde he estado esperando la redempción entre la cruz y el agua bendita, desahuciado de que la santidad y Milagros del Venerable frayle me fuesse favorable (a lo que de justicia) me pertenezía. Me ha tenido en la Piscina de su cerviz indomable asta que el Angel que nos gobierna me ha zambuIlido para liberarme de la lepra, y barrido quasi toda la basura de mis deudas.

Por fín, Palanco amoroso, yo me voy a Nápoles, y si no muero, a hartarme de Macarrones y queso. .."

El marqués de la Victoria trajo hasta Barcelona a la real familia en El Fénix ${ }^{40}$. Quedó sorprendido y encantado por los detalles y la generosidad de D. Carlos, ya que en Nápoles le honró con el Cordón de San Genaro; antes de Ilegar le

37. 28 de febrero de 1759

38. 27 de junio de 1759

39. 20 de mayo de 1759

40. No debía ir tan descarriado nuestro marqués en sus críticas, ya que ante el deplorable estado de los marinos, la tripulación encargada de ir a recibir al nuevo rey fue uniformada de un azul riguroso a expensas de S.M.

DESDEVIZES DU DECERT, G.: La España del Antiguo Régimen, Madrid, 1989, p.555 
dio un bastón de oro y le hizo capitán general de su Real Armada y de tierra, le regaló 30.000 pesos y un retrato guarnecido en brillantes valorado en otros 14 ó 15.000 pesos $^{41}$. Tanta alegría no le hizo olvidar que su problema era el bailío, y de nuevo se refería a él con resentimiento:

"Palanco de mi corazón... el Baylío me ha declarado la guerra, y yo no te quiero cansar refiriéndote uno por uno sus defectos, su soberbia y su mala correspondiente amistad con que me escribía de su puño cada Correo, pues se ha experimentado falsa, y solo por sacarme documentos sobre el ofizio que haze y no entiende, eran sus expresiones. Ya te he referido las tramoyas que puso en obra para que yo no fuesse al Vuaje de Nápoles. Dios y el Rey lo disposieron como ha sucedido. Yo no puedo passar a essa Corte que a fines de Marzo, que desvaneciera todo lo que impone al Rey (que me asseguró de que nadie me desquiciara de su Real gracia) sobre puntos de Marina y su Gobierno. Picado esse santurrón fingido de que yo me explico en las cartas de oficio con la verdad, pues aquí me han tratado como un mero Comandante de Departamento, me escribió días passados que el Rey quería saber en qué se me havían quartado las autoridades que me da la Ordenanza. Le he respondido escribiéndole al Rey, que a mi no se me participava que lo que el Ministro quería, pero en punto de conocimiento de armamentos, Arsenales, sus Depósitos, etc que no sabía nada. No se lo que resultará.

Como temo que esse bendito $S$. Juanista no enseñe la carta al Rey, y solo por mayor su contenido, ofreciéndoseme ahora de escribir en respuesta de una carta en que el Baylío passó al Consejo de Guerra la causa de D. Pedro de Mora, ayudante de Guardias Marinas, convencido de adulterio público con una mujer de un Oficial benemérito de su mesma Graduación, por cuyo motivo esse Obispo le dio carta de Divorcio, de haverla inducido a dar veneno a su marido, a su mismo Padre y aun de haver intentado hazer rapto de ella, de haverse huido a una torre donde de mi orden estava preso, de haverle la Inquisición procesado por blasfemo, aunque se retra(. . .)

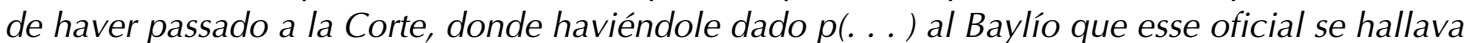
allí, y que era desertor y escalador de Muralla, por consideración que era Pariente del Gobernador del Consejo, y por tanto, su pariente, ni lo mandó prender y lo que hizo fue con la escusa que havía apelado al Consejo, passarle todos los Documentos, que pertenecientes a mi juzgado y aún al suyo, como Ministro de Marina, pues nuestra Ordenanza manda que solo en causas civiles pueden los oficiales apelar al consejo de Guerra.

. . . Si el Rey piensa tener un Santo por Ministro de Marina, yo le desengañaré quando vaya a besarle sus Reales manos ${ }^{42}$

Estaba claro que nuestro personaje no congeniaba con sus superiores. Ninguno de los tres ministros (Patiño, Campillo y Ensenada) lo quiso a su lado, aun reconociendo su indudable preparación y valía. Él, era consciente de ello y maldecía su mala estrella:

"me lisonjea mi amor propio que he hecho algunas cosas en el Servicio de algún mérito, pero no sé qué Diablo tiene mi Angel de Guarda con los de los Ministros, que luego al punto que lo son le buelben el extergo. Si fue Patiño, me descompuso con la Reyna Viuda diziéndole que auqnto me confiavan los Reyes todo se lo iba a contar a nuestros Príncipes, oy día Reynantes, y que esto Sus Magestades no lo ignoran. En tiempo del Sr. Ensenada, me tomaron por la Proa, porque me opuse a que no se perdiese (como injustamente desseavan) al Sr. D. Andrés Reggio. Y ahora que hay un Ministro del mesmo Cuerpo de Marina, tiene un corazón tan elado y tan corito, que todos los hornos y caleras del Mundo, aunque entre el de Babilonia, no lo calentarán a dar un passo a favor de uno". ${ }^{43}$

41. 4 de diciembre de 1759

42. 1760

43. 7 de marzo de 1757 


\section{Apunte final}

A lo largo de esta extensa correspondencia que reúne 42 cartas chispeantes, nos ha permitido conocer un poco más la intrahistoria de este excepcional hombre que abarcó las más variadas ramas del saber, siendo un pantófilo de su tiempo.

No alcanzó el relumbre que su genio creativo merecía y murió en la mayor necesidad, hasta el punto que a su muerte, la corona hubo de correr con los gastos de su sepelio y condonar a sus herederos la deuda de 23.900 reales de vellón que tenía en descubierto por pagas anticipadas ${ }^{44}$.

Su título le hizo honor a lo largo de su dilatada existencia, porque la suya fue una "victoria" sobre el conocimiento y la vida; culto, mordaz, resentido e irónico hasta con su mala suerte:

". . . por ver si encontrando la mandrágora ( ya que por mi poco valer he sido el blanco y el negro de los Ministros) podía con ello caer en gracia de ellos. Pero por mi desdicha ellos han sido culos y yo ortiga. Porque en acordándose que vivo luego disparan, diciéndome el refrán de lo que el culo dijo a la ortiga: ¡ya te conozco, mala hierba!" 